\title{
Human Evolutionary Carcinogenesis and Effects of Demographic and Epidemiologic Transitions in Low- and Middle-Income Countries
}

\author{
Armando E. Pérez-Cala MD MS and Edgar Benítez-Sánchez MD MS
}

\begin{abstract}
INTRODUCTION In many countries cancer is or threatens to become the leading cause of death, although incidence and mortality rates differ between high-income and low- and middle-income countries. Developments in evolutionary biology have revealed that carcinogenesis is even more complex than previously thought. Several theories attempt to integrate the various existing points of view about what is known to date.
\end{abstract}

OBJECTIVES Analyze and explain the main current theories of carcinogenesis and explore their possible application to understanding the demographic and epidemiologic transitions' effects on cancer population dynamics in low- and middle-income countries.

EVIDENCE ACQUISITION A systematic literature review was carried out in MEDLINE (via PubMed), SCOPUS (via ScienceDirect) and SciELO. Consistency and quality of evidence in articles reviewed were taken into account; we excluded studies with consistency levels of IV and V, and those with limited or insufficient quality of evidence.

DEVELOPMENT Human evolution has led to a type of life history characterized by numerous tradeoffs with oncogenic implications.

\section{INTRODUCTION}

Cancer incidence and prevalence are increasing, and in many countries cancer threatens to become the leading cause of death. In 2008, 12 million new cases of cancer and 7.6 million deaths were recorded worldwide; $56 \%$ of cases and $64 \%$ of deaths occurred in low- and middle-income countries (LMIC). $[1,2]$ Currently, about 14 million new cases are reported each year.[1,2] Cuba's pattern is that of a high-income country, with high rates of cancer incidence, and between 20,000 and 25,000 new cases diagnosed every year. Cancer is the leading cause of death in the population aged 15-64 years. [3] Another important indicator of cancer's negative impact at the population level in Cuba is disability-adjusted life years in the reproductive age group. For example, in the group aged 15-44 years, disability-adjusted life years for breast cancer went from 146.9 per 100,000 population in 1990 to 227.8 per 100,000 in 2006.[4]

Two phenomena are major contributors to the global oncological epidemic: population increase and population aging (known as the demographic transition), which translates to greater numbers of people in the age groups at highest cancer risk; and greater environmental and behavioral exposure to known cancer risk factors. The combined effects of the demographic transition and increased risk factor exposure are observed in increased cancer incidence, prevalence and burden, and in chronic non-communicable diseases surpassing infectious diseases as leading causes of death (known as the epidemiologic transition).[5-11]
Cultural coevolution and socioeconomic development have affected cancer population dynamics. Several theories explain carcinogenesis from an ecological and evolutionary perspective, among them somatic mutation, adaptive oncogenesis, life history theories, and the Noble and Hochberg model. The human environmental effect on cancer risk is manifested in the influence of demographic and epidemiologic transitions in low- and middle-income countries, where cancer represents a high disease burden due to the effects of recently introduced environmental factors in native environments, accentuation of adaptive decoupling, and diversification of genetic polymorphisms for cancer susceptibility.

CONCLUSIONS The Noble and Hochberg model best explains the population dynamics of cancer in low- and middle-income countries, especially regarding the effects of recently introduced environmental factors on native environments, adaptive decoupling and genetic diversity (manifest in differences in clinical and biological tumor expression by level of economic development), in response to demographic and epidemiologic transitions.

KEYWORDS Carcinogenesis, oncogenesis, tumorigenesis, population dynamics, health transition, biological evolution, cultural evolution, life history theory, Cuba

Beginning in the 1950s, a new vision of cancer began to develop, an ecological and evolutionary vision. The idea of cancer as a result of the accumulation of "harmful humors" within the body or a "hormonal imbalance" was left behind.[12] Years of laborious research have led to the definition of cancer as an evolutionary process, called somatic evolution (evolution within the body) governed by Darwinian laws (variation, differential natural selection, degree of fitness for adaptive success, etc.), the paradigm of what is now known as evolutionary cancer biology.[12]

This conceptual revolution about the mechanisms underlying carcinogenesis has, however, brought new theoretical and practical challenges, mainly regarding a definition of carcinogenesis (whether due to an intrinsic propensity of cells or a consequence of an environmental effect) and differences between high-income countries and LMICs in epidemiologic patterns of cancer. The objectives of this systematic review focus on critically discussing the following questions: What are the main theories that explain carcinogenesis from an ecological and evolutionary perspective? Could some of them shed light on the effects of the demographic and epidemiologic transitions on population dynamics of cancer in LMICs?

\section{ACQUISITION OF INFORMATION}

The literature databases consulted and search engines used were MEDLINE (via PubMed), SCOPUS (via ScienceDirect) and SciELO. In addition, a search was made using the Tree of Science software (http://www.treeofscience.com/), which combines classic structural papers (trunks) and recent articles 
(leaves) related to search terms, and identifies important papers retrieved with the MeSH terms used. Keywords used were carcinogenesis, evolution and cancer, and cancer population dynamics. By reviewing references of the publications selected, new keywords were identified and incorporated: mutationselection balance, Peto's paradox, tradeoff, life history theory, adaptive oncogenesis.

Exclusion and inclusion criteria Articles published during 2005-2017 were included; articles considered classics were selected regardless of publication date. Study type, authorship, results and limitations were also considered. Studies with consistency levels IV and V (level IV: descriptive studies that include analysis of results; level V: case reports, expert opinions, consensus statements) were excluded; as well as those with limited evidence (few studies available to support results, inconsistencies in results) and insufficient evidence (study number and quality too limited to clearly classify information).[13]

Articles that met inclusion criteria were entered in a table of evidence and distributed by author and year; level of evidence, study design, participants and inclusion criteria; list of measures related to review objectives; and results.[13] From 122 articles reviewed, 50 were selected, in consultation with 5 experts (1 from the Scientific Council of the Military Hospital of Santiago de Cuba, 2 from the Council of Scientific Societies of Santiago de Cuba, 1 from the Biology Department of the University of Oriente, and 1 from the Biology Department of the Cuban Ministry of Science and Technology delegation in the province of Santiago de Cuba).

\section{DEVELOPMENT}

Carcinogenesis: from chance to causality In 2015, two eminent cancer researchers, Tomassetti and Vogelstein, published an article that stirred considerable controversy. The title itself had a strong impact: Variation in cancer risk among tissues can be explained by the number of stem cell divisions. [14] From the correlation between cancer risk and the number of cell divisions calculated in the group of tissues studied, the authors concluded that human tumors may be classified into two causal categories:

- Deterministic tumors (or D tumors): those closely related to environmental factors-such as exposure to solar radiation, tobacco and oncogenic viruses-and those due to a genetic predisposition (hereditary cancers).

- Replicative tumors (or R tumors): tumors without an obvious link to environmental or hereditary factors, but explained by the accumulation of mutations during replication of stem cell DNA throughout life. These cancers were also called "bad luck" tumors.[14]

According to their calculations, two thirds of all human neoplasms would be R, or "bad luck" tumors, so they concluded that the number of stem cell divisions throughout life sufficed to explain most human cancers. Over time, tissues with greater numbers of stem cell divisions accumulated the mutations necessary for cancer development. According to the authors, in D tumors, the environmental or hereditary effect would contribute by adding to the risk already implicit in genetic errors that accumulated in stem cells during their divisions.[14]
In March 2017, Tomassetti and Vogelstein published a study of tumor samples from patients in 69 countries, to reduce environmental uniformity (their first study used a US population) and to explore environmental variation and influence on the etiology of the various cancers reviewed (in addition to climate, exposure to carcinogens, economic development, health system, etc.).[14] The results confirmed the findings of their 2015 study.[15]

Their conclusions triggered numerous objections based on countervailing evidence and on mathematical and statistical analyses that demonstrated methodological deficiencies in both works.[16-22] Most criticisms were directed at their excessively stochastic view of carcinogenesis, which downplayed the importance of environmental influences and hence, the value of preventive measures. However, Tomassetti and Vogelstein's conclusions have to be looked at in light of an ecological and evolutionary perspective on carcinogenesis. Its historical antecedents lie in the pioneering work of Armitage and Doll, who observed a relationship between age and risk of certain types of tumors and, based on their observations, developed the multistage carcinogenesis model,[23] which later gave way to somatic mutation theory.[12]

Somatic mutation theory regards tumor development as a cumulative sequence of mutational or epigenetic events (acquired changes at the genomic level that do not modify genetic structure, but do modify its expression, and whichlike mutations-are inherited). Such changes are called driver mutations, since they increase the adaptive advantages of cells carrying them.[24] The appearance of each driver mutation marks the passage from one phase of tumor development to another, because, when it becomes fixed at the population level, it confers a new quality to the tumor (higher proliferation rate, immunological resistance, tolerance to hypoxic environments, etc.). In turn, a driver mutation, by triggering clonal expansion of malignant cells carrying it, increases the probabilities that the clones will acquire new driver mutations.[25]

For a tumor to progress through its development, it would have to acquire one or more driver genetic changes, which confer greater degree of fitness, allowing it to surmount each phase of progression.[24-26] Degree of fitness refers to the ability of an individual, at any taxonomic level (eukaryotic cells, bacteria, multicellular organisms), to achieve adaptive success; that is, to reproduce and transmit their genes to successive generations.[12] The essence of somatic mutation theory can be summarized as the sequential and progressive accumulation of driver genetic changes over time, until mutated cell populations acquire all the phenotypic traits of cancer. These genetic events take place over decades, and their probabilistic nature explains why organisms with greater longevity are more susceptible to emergence and complete development of malignant tumors. In sum, the longer the life, the greater the chance of successful carcinogenesis.[24]

Another approach based on the hypothesis of adaptive oncogenesis, holds that oncogenic mutations and the degree of adaptive advantage or disadvantage conferred on affected cells depend on the ecological context in which they occur. [27-30] It is not enough that the cell undergo driver mutations; 
these mutations must have repercussions on the cellular microenvironment. The cellular microenvironment is formed by other cells that share the tissue compartment, the extracellular matrix, and soluble factors that enable interaction between cells forming the compartment.[27,28] In healthy tissues-as young tissues usually are-any oncogenic mutation is eliminated from the cellular compartment or is restricted by the greater degree of fitness of the other cells. However, deterioration of the cellular microenvironment, as happens during aging or exposure to environmental carcinogens, exerts strong selective pressure. Only then, are oncogenic mutations that provide adaptive advantages fixed at the population level and transmitted to descendant cells, giving rise to tumor initiation.[29,30]

Unlike multistage carcinogenesis, adaptive oncogenesis does not consider tumor development a progressive and sequential accumulation of genetic changes, but as influenced by ecological modifications of the cellular microenvironment. Its postulates emerged in light of new discoveries, such as: mutation accumulation rates highest during early stages of development (about $50 \%$ of oncogenic mutations occur during childhood and adolescence); oncogenic mutations often detected in otherwise healthy tissues; and evidence of clonal selection and expansion in normal cells that do not become neoplasms. These and other facts cannot be explained by multistage carcinogenesis. The theory of adaptive oncogenesis postulates the strong dependence of tumor progression on environmental influences and the ecological context of the cellular compartment.[29]

In our opinion, Tomassetti and Vogelstein commit a logical fallacy derived from the traditional conception of somatic mutation theory, which is based on the progressive and deterministic accumulation of driver mutations. They also ignore the influence of individual differences on the ultimate expression of population adaptations to environmental challenges (ecological fallacy), as Sornette and Favre demonstrated.[21]

Peto's paradox and human evolutionary carcinogenesis The larger a multicellular organism is and the longer it lives, the greater should be the likelihood of developing a malignant tumor.[31] But Peto demonstrated that there is no correlation between body size, life span, and cancer risk along the phylogenetic continuum of mammalian species. Exhibit $A$ : the blue whale has a much lower incidence rate of malignant tumors than humans. Why does the blue whale, with many more cells than a human, not have greater risk of cancer?[31] Among the theories that try to explain Peto's paradox, life history theory is the most widely accepted.[32]

Cancer and analogous forms of cellular homeostasis disruption (alterations of cellular cooperation resulting in uncontrolled proliferation and altered differentiation that disharmonize multicellular architecture) are phenomena that affect several biological categories, from sponges to chordates, and even plants.[33] Such extensive incidence has suggested to evolutionary biologists the importance of cancer as an ecological and evolutionary phenomenon.[33]

The meaning of carcinogenesis as an ecological and evolutionary process affecting organisms in natural habitats is not straightforward; nor is its application to the understanding of human carcinogenesis. Several theories have emerged. [32-36] Modifiable environmental conditions give particular characteristics to different ecological systems or niches and, in turn, require that organisms dwelling in them adapt.[32,34] During the process of adaptation, organisms evolve, and that evolution determines patterns of life history, with their specific strategies in distribution and utilization of energy produced by the organism. Use of energy, in principle intended for somatic maintenance, can vary depending on type of life history, as determined by evolution.

There are organisms forced to invest their energy in growing rapidly, reproducing, and almost immediately dying. These are organisms with "short" life histories.[32] At the other extreme, there are species with "long" life histories, that go through a long maturation period before reaching their reproductive stage, so that progeny require prolonged parental care before achieving biological independence. Such organisms need to continually renew and monitor their state of cellular homeostasis. Their energy use is under constant strain, because they need to both conserve it and to use it for maintaining cellular homeostasis and basic functions (growth, sexual maturation and reproduction).[35,36]

It is somatic maintenance that ensures conservation of cellular homeostasis, and thus reduced risk of developing cancer. It involves supervision of the cellular state; balanced regulation of division, aging and cell death processes; tissue damage repair; genomic damage repair; and immunological surveillance.[32] There is a plausible explanation for Peto's paradox: evolution selects large organisms and long life histories, provided they have sufficiently effective anticancer mechanisms to allow them to reach healthy reproductive age (having survived noncancerous causes of mortality). It has even favored genes that increase reproductive potential although they may be oncogenic.[34-36] This is known as tradeoff: optimization of a trait that confers adaptive fitness to the detriment of another or others.[37] Theories based on life history consider the human being a "big organism with a long life history."[32]

Human evolution has been characterized by a high number of tradeoffs with oncogenic implications: bipedalism, which resulted in skin more vulnerable to the mutagenic effect of ultraviolet radiation and requiring better heat dissipation; switching from a vegetarian to an omnivorous diet, and then cooking food, which resulted in ingestion of nitrosamines and polycyclic aromatic hydrocarbons; promiscuous sexual behavior to ensure a greater number of offspring, causing spread of oncogenic viral infections; need for greater parental care to safeguard the long prereproductive maturation period of offspring accompanied by delayed aging and accumulation of harmful mutations throughout life; need to ensure greater female fertility, given the relatively small number of offspring capable of reproducing, which resulted in population-wide prevalence of carriage of BRCA1 and BRCA2 genes (These increase fertility, but also increase breast cancer risk).[36] Added to these biological factors are cultural factors associated with industrialization, demographic expansion and toxic habits, with negative health consequences.[37] The various life history theories emphasize that patterns of human carcinogenesis are determined by evolution. 
And the environmental effect? Hochberg and Noble's integrated model analyzing how the environment influences carcinogenesis starts from the principle that in natural habitats baseline cancer risk does not exceed $5 \%$, and that any increase above this reference value is due to an environmental effect.[38] Recently introduced environmental factors characteristically impact on the cancer risk of individuals who have adapted to their native habitats. Importantly, this model argues that newly introduced environmental factors (including behavior) determine cancer risk at three basic levels: body (altering body size and longevity); within the organism (disrupting metabolic and physiological processes), and at the genomic level (determining population perpetuation of tumor susceptibility genes), that is, disrupting life histories.[38]

The Hochberg and Noble model posits that human evolution has resulted in substantial deviation from baseline cancer risk in native habitats (environments experienced over evolutionary time), both for the human species and for animals that have participated in or been affected by our historical development. [38] This deviation from individual fitness, expressed as an increased risk of cancer, is mainly due to establishment of protected environments (environments with few or no natural selective pressures), which in turn led to larger body size (current humans exceed our premodern ancestors by $19 \mathrm{~cm}$ ) and life expectancy (by about 40 years).[38] Consequently, human bodies have both more cells and more time available for carcinogenesis to develop.

The term "protected environment" should be considered cautiously, and probably the authors do not use it in a literal sense. While for captive or domesticated animals it means a change of habitat in which natural predators and parasites no longer determine risk of death, for homo sapiens it has brought oncogenic influences (harmful lifestyles, atmospheric pollution, industrial carcinogens, etc.) along with its undeniable benefits. One evolutionary biologist, Greaves, argues that the high prevalence of lymphoid neoplasms in children and adolescents in high-income countries responds to a protected-environment effect; that is, it occurs where hygienic and sanitary conditions have improved enough to almost eradicate childhood infections. Paradoxically, the immune systems of these children and adolescents suffer maturation disturbances that cause malignant proliferative disorders.[39]

The model provides an integrative theoretical framework for understanding how environments contribute to cancer at three levels: the organism itself, processes within the organism and the genome. Taken as a whole, it suggests that human evolution has markedly diverted the species from its baseline cancer risk, which has increased to about $40 \%$ lifetime risk, compared to the estimated $5 \%$ for organisms in natural habitats. Nevertheless, the model seems to suggest that the process has reached stability. However, regarding the human environment itself, the population level and in its sociodemographic and economic variations, are there still no recently introduced environmental factors that influence baseline cancer risk?

The main features of the theories discussed are summarized in Table 1.
Cancer incidence and mortality in LMICs: recently introduced environments versus native environments Demographic and epidemiologic transitions in LMICs take place in a complex socioeconomic context and at variable rates. In some countries, infectious and chronic non-communicable diseases have similar incidence, prevalence, and mortality; in others, cardiovascular diseases and cancer compete for first place in these indicators. $[5,11]$ At the same time, globalization of the so-called western lifestyle introduces risk factors such as smoking, obesity, physical inactivity and unhealthy nutritional habits.[11]

It could be said that there is an "oncological transition" in LMICs, produced by the combined effect of the demographic and epidemiologic transitions. In Africa, for example, cervical cancer is the leading cause of cancer death in women. Liver carcinoma is the second most diagnosed cancer and the leading cause of cancer death in African men in the continent, and the third most frequent cancer and third leading cause of cancer death in African women. Kaposi's sarcoma is the most frequent cancer in men and third in women in East Africa. Esophageal cancer, the leading cause of cancer death for both sexes in the continent, predominates in eastern and southern African countries. These tumors share common features of being associated with infectious agents, poor dietary habits, and unfavorable economic conditions that have characterized the continent throughout recent history.[7] These circumstances make it possible to classify them as representatives of baseline human cancer risk at a regional level.

The epidemiologic transition is beginning to modify Africa's cancer landscape. During 2008, 715,000 new cases of cancer and 542,000 deaths were recorded in Africa, and the numbers are expected to double by 2020 because of population growth and aging.[7] Breast, lung and prostate cancer incidence has increased in the African countries with highest development indices, where the epidemiologic transition is under way. Thus, lung cancer is the leading cause of cancer death in northeastern African men, and the 4th in southeastern women, areas with high smoking prevalence; and $65 \%$ of lung cancer cases in these areas are related to smoking, a proportion not very different from that of Western countries.[7]

Female obesity in Africa is highest in countries with better economic conditions (Egypt, for example, where 29\% of women are obese) and breast cancer incidence is increasing proportionately.[7] With respect to breast cancer, Brinton adds to the list of previously identified native breast cancer risk factors in sub-Saharan Africa (multiparity-contrary to other parts of the world-greater height, and increased waist circumference), recently introduced risk factors, such as hair relaxers and skin-lightening creams rich in estrogenic hormone compounds (hydroquinones), and, in areas of intense malaria infection, exposure to the insecticide DDT.[40]

Hochberg and Noble assert that baseline cancer risk reflects long-term development of adaptations to environmental conditions, likewise prevailing over long periods, which means that risk from a new environmental factor varies considerably in the absence of a substantial evolutionary response (a phenomenon called "adaptive decoupling").[38] Socioeconomic 
Table 1: Comparative summary of four theories

\begin{tabular}{|l|l|l|l|l|} 
Theory & Rationale & $\begin{array}{c}\text { Weighting of } \\
\text { environmental } \\
\text { effects }\end{array}$ & $\begin{array}{c}\text { Level } \\
\text { of explanation }\end{array}$ & $\begin{array}{c}\text { Adhesion to evolution- } \\
\text { ary principles }\end{array}$ \\
\hline
\end{tabular}

Proposes intrinsic predisposition of cells to spontaneously accumulate oncogenic

Somatic

Accumulation over time of mutations that increase mutation[12,24-26] cellular fitness (driver mutations)
Interprets evolutionary principles in mechanistic and deterministic way. mutations independent of environment.

Does not recognize empirical evidence demonstrating carcinogenic effects of environmental agents.

\begin{tabular}{|c|c|c|c|c|c|}
\hline $\begin{array}{l}\text { Adaptive } \\
\text { oncogenesis[27-30] }\end{array}$ & $\begin{array}{l}\text { Oncogenic mutations } \\
\text { depend on tissue ecologi- } \\
\text { cal context }\end{array}$ & Important & $\begin{array}{l}\text { Genomic } \\
\text { Cellular } \\
\text { Tissue } \\
\text { microenvironment }\end{array}$ & $\begin{array}{l}\text { Adequately considers } \\
\text { concepts of evolutionary } \\
\text { dynamics (effect of varia- } \\
\text { tions on degree of fitness, } \\
\text { natural selection, genetic } \\
\text { drift, migration, etc.). }\end{array}$ & $\begin{array}{l}\text { Does not establish relation- } \\
\text { ship with phenomena on } \\
\text { larger scale (human socio- } \\
\text { economic environment as } \\
\text { ecological environment that } \\
\text { impacts cancer risk and its } \\
\text { effects on degree of fitness). }\end{array}$ \\
\hline Life history[32-36] & $\begin{array}{l}\text { Use of energy for vital } \\
\text { needs according to devel- } \\
\text { opment pattern defined } \\
\text { by evolution (life history) } \\
\text { determines baseline cancer } \\
\text { risk }\end{array}$ & Important & $\begin{array}{l}\text { Cellular } \\
\text { Organism }\end{array}$ & $\begin{array}{l}\text { Emphasizes outcome of } \\
\text { evolution and adaptive } \\
\text { mechanisms. }\end{array}$ & $\begin{array}{l}\text { Still no reliable data on can- } \\
\text { cer incidence, prevalence, } \\
\text { and effect on degree of } \\
\text { fitness of life forms in natural } \\
\text { habitats. }\end{array}$ \\
\hline Integrated model[38] & $\begin{array}{l}\text { Effect of novel environmen- } \\
\text { tal factors that alter devel- } \\
\text { opment pattern defined by } \\
\text { evolution (life history) and } \\
\text { exert influence on baseline } \\
\text { cancer risk }\end{array}$ & Important & $\begin{array}{l}\text { Genomic } \\
\text { Cellular } \\
\text { Organism } \\
\text { Population }\end{array}$ & $\begin{array}{l}\text { Integrates evolutionary } \\
\text { principles at various } \\
\text { biological levels. Recon- } \\
\text { cilable with constantly } \\
\text { changing global evolution- } \\
\text { ary population phenom- } \\
\text { ena. }\end{array}$ & $\begin{array}{l}\text { Establishes that recently } \\
\text { introduced factors, although } \\
\text { determined by human } \\
\text { evolution, have established } \\
\text { a "new normal" for baseline } \\
\text { cancer risk. Demographic } \\
\text { and epidemiologic transitions } \\
\text { in LMIC demonstrate that the } \\
\text { process is continual and at } \\
\text { variable rates. }\end{array}$ \\
\hline
\end{tabular}

and demographic changes are occurring in many countries amidst native habitats characterized by traditional cultural traits (some of which are unhealthy), social inequity and low medical coverage; such changes further accentuate adaptive decoupling, which would explain this contrasting epidemiologic mosaic of cancer in Africa.

We believe, as do other authors, that statistics from LMICs, although still fragmented and incomplete (many are based on regional models for making general estimates), allow us to trace useful cancer incidence and mortality patterns. $[7,8]$ They are sufficient to allow us to conclude that advent of the epidemiologic and demographic transitions in LMICs acts as a new factor that continues to modify cancer risk. The Hochberg and Noble model could and should incorporate this aspect of human carcinogenesis.

Hispanic paradox or natural selection effect? Some studies indicate a degree of protection against some types of cancer in Hispanic Americans (immigrants or descendants of individuals from Latin America and the Caribbean). In a large, prospective, lung cancer screening study (sample size 53,000), Tammemägi found a relative risk of 0.48 for Hispanic vs. Caucasian Americans, after adjusting for age, smoking history and education (relative risks for African and Asian Americans were 1.48 and 0.63 , respectively).[41] This is known as the Hispanic paradox.[42]
Several theories are proposed to explain this apparent protection (which extends to cardiovascular diseases, and is even demonstrated in higher life expectancy for Hispanic residents in the USA), from genetic, nutritional and sociocultural factors, to the hypothesis of immigration of the fittest.[42] However, there are contradictory results, such as the fact that Latinos who return to their countries of origin are three times more likely to get sick than their compatriots who never emigrated, and that the advantageous life expectancy of Hispanic immigrants in the USA decreases rapidly-whether because the second generation adopts lifestyles typical of the USA, or due to a balancing selective pressure that keeps population genetic stock stable by opposing natural selection-_and they begin to show the same mortality rates for chronic non-communicable diseases (including cancer) as the native US population. $[6,42]$

However, in our opinion, this mention of differences in risk, incidence, and prevalence of cancer among people of diverse ethnicities and sociocultural backgrounds serves as starting point for other evolutionary considerations about cancer. We should not forget that individual variations (at all biological levels) are essential for interacting with the environment and the ensuing evolutionary process. Humans are no exception. That is why varying degrees of vulnerability to cancer are expressed in different socioeconomic environments, and tumor biological patterns are diverse even within the same organ. For 
example, the increased incidence of prostate cancer in the male Chinese population is closely related to a parallel increase in per capita consumption of animal fat, up by $128.6 \%$ from the 1960s to the year 2000.[43] Moreover, it is remarkable that of 76 identified genetic polymorphisms (variations in specific DNA sequences that produce multiple gene alleles in a population) of susceptibility to prostate cancer, 10 have been found in Chinese men.[43]

Genetic polymorphisms are also described in breast cancers in Asian women, distinguishing them genetically, biologically and clinically from breast cancers in Western countries.[44] In some regions of Africa, there are case series of breast tumors that occur earlier in life, are negative for hormone receptors, have poor HER 2 oncogene expression, are detected in advanced stages and have worse prognosis than other types.[45] This tumor variant is also characteristic of African-American women in the USA and the United Kingdom; and may represent a founder effect (the formation of a new population of individuals from a very small number of ancestors). Noble and Hochberg suggest it is a genetic consequence of the impact of recently introduced environmental factors that perpetuate oncogenic genes at a population level. However, this view is not universally supported.[45]

The foregoing highlights that the epidemiologic and demographic transitions in LMICs exert strong selective pressure, which in turn displays variations in population response to its influence.

Cancer incidence and mortality in LMICs and their effects on adaptive fitness: contextualizing Darwin Another essential idea put forward by the hypothesis of adaptive oncogenesis is that many mutations reduce, rather than increase, the degree of individual fitness. Only ecological disruption of the environment (cellular microenvironment in the case of carcinogenesis) would confer fitness.[30] Is it possible to speak of a human population macroenvironment (biological, regional and socioeconomic) in which cancer influences degree of fitness?

In evolutionary terms, fitness is defined by the ability to procreate and genetically transmit information to subsequent generations. At the population level, the degree of fitness is also expressed by competitiveness within the population (that is, higher probability of reproducing, independent of resource availability, number of individuals, geographic space, etc.). In this regard, Rozhot and DeGregori suggest that within the tissue compartment, stem cells must have the ability to maintain, reduce, or expand their numbers in accordance with environmental requirements, including those of other cell populations.[30] If we generalize these principles, most human tumors emerge in the advanced postreproductive stage, and protected environments have led to an extension of this stage, through reduced risk of death from other causes (cardiovascular and cerebrovascular diseases). In other words, many humans exceed the ecological limits established for their age group and survive noncancer causes of death, due to human intervention that has increased control of previously lethal diseases. Therefore, tumor development would be an intrinsic component of aging that does not have repercussions on degree of fitness. However, two elements must be considered. The first has to do with observations that some tumors detected in very old age are less malignant (including lower metastatic capacity); something like "very old tumors in very old people."[46] We might speculate whether these types of cancers are characteristic of a life expectancy carried beyond what is "natural." In evolutionary terms, we think the answer is yes, in the long term: in the elderly these low-malignancy tumors could be the final result of current trends in industrialized countries to reduce both incidence and mortality, at least for some of the most frequent tumors and for other chronic non-communicable diseases.[1,5,6] The second element comes precisely from observations that limit generalization of the above. By modifying lifestyles, even in the elderly, many of these late-onset tumors (breast, lung, prostate) can be prevented; perhaps, leaving certain varieties of leukemias and lymphomas as tumors inherent to advanced age (and not, by the way, benign ones).[46]

Acknowledging the risks of extrapolating principles from one biological taxonomy scale to another, let us consider the following aspects of cancer's impact on human fitness: age-specific incidence, relationship between incidence and mortality and socioeconomic implications of these parameters in LMICs. Let's take the example of breast cancer in Latin America and the Caribbean.

Amadou and Villareal-Garza, among others, agree on several epidemiologic aspects of breast cancer in Latin American and Caribbean women: presentation at younger ages (up to a decade earlier than in women from high-income countries); high malignancy; detection in advanced stages; higher prevalence of BRCA1 and BRCA2 mutations (up to $25 \%$ of cases, in contrast to the $10 \%$ reported in high-income countries), and even the existence of a founder effect in Mexican women.[47,48] Incidence rates increased throughout Latin American in the period 1980-2010.[49] There have been attempts to explain breast cancer's higher burden at earlier ages by differences in regional age distribution compared to industrialized countries, but Franco-Marina points out that, although age-specific incidence rates are higher in Canada and the US, incidence in young Latin American women is increasing faster.[50] Villareal-Garza found proportions of incident breast cancers and breast cancer deaths in women aged $\leq 44$ years higher in Latin America than in high income countries (20\% vs. $12 \%$ for incident cases and $14 \%$ vs. $7 \%$ for deaths). [48] RochaBrischiliari reported a significant increase in breast cancer mortality in Brazilian women aged 20-49 years in 1999-2013, although with marked regional differences, and higher in rural areas.[51] Although there is debate on whether these numbers reported in registries are due to ethnic variations, there is no doubt that they represent a greater cancer disease burden, with the attendant social and economic consequences.

Beyond biology, most studies suggest that late breast cancer detection (i.e., detection in advanced stages) in Latin American women is due to precarious access by the most disadvantaged social sectors to screening tests, low perception of risk due to poor health information, and, finally, to underlying socioeconomic inequities. It is widely agreed that prevention is the most plausible approach to reducing this disproportionate burden.[47-50] However, many countries in the area confront a vicious circle of poverty and lack of education, insufficient capacity to capture 
and analyze information about cancer as a health problem, and limited possibilities for effective preventive measures. To these are added higher incidence, and limited access to health services and disease detection in advanced stages, which together increase mortality and decrease survival times.[11]

The abovementioned statistics and considerations show the effect of demographic and epidemiologic transitions in the midst of a deteriorated macroenvironment, favorable to oncogenic factors influencing individual fitness. Adaptive oncogenesis can range from effects associated with carcinogenesis at the tissue microenvironmental level to contextual effects of the socioeconomic macroenvironment at the population level.

It is not necessary to arrive at Tomasseti and Vogelstein's carcinogen-free "Planet B"[15] to demonstrate the environmental effect of human activity on human evolution, past and present. Demographic and epidemiologic transitions, rather than "bad" or "good" phenomena, are inescapable facts. In brief, on our planet, and especially in LMICs, cancer is, in Cavalli's words, "a great challenge."[52]

\section{CONCLUSIONS}

Of the four theories reviewed, Noble and Hochberg's integrated model is the most robust and best explains observed cancer patterns in LMICs, especially regarding the effects of recently introduced environmental factors on native environments, adaptive decoupling and genetic diversity (manifest in differences in clinical and biological tumor expression by level of economic development), in response to demographic and epidemiologic transitions.

\section{ACKNOWLEDGMENTS}

The authors thank Dr James DeGregori for critical review and timely comments on the manuscript. -1 -

\section{REFERENCES}

1. Ferlay J, Soerjomataram I, Dikshit R, Eser S, Mathers C, Rebelo M, et al. Cancer incidence and mortality worldwide: sources, methods and major patterns in GLOBOCAN 2012. Int J Cancer. 2015 Mar 1;136(5):E359-86.

2. Jemal A, Bray F, Center MM, Ferlay J, Ward E, Forman D. Global cancer statistics. CA Cancer J Clin. 2011 Mar-Apr;61(2):69-90.

3. National Health Statistics and Medical Records Division (CU). Anuario Estadístico de Salud 2016. Havana: Ministry of Public Health (CU); 2017. 206 p. Spanish.

4. Domínguez E, Santana F, Seuc AH, Galán Y. Años de vida ajustados por discapacidad por cáncer de mama y del sistema reproductor en mujeres cubanas en edad fértil. MEDICC Rev [Internet]. 2014 Jul-Oct [cited 2016 Oct 23];16(3-4). Available from: http://www.medicc.org/mediccreview/index .php?issue $=36 \& i d=480 \& a=v a$. Spanish .

5. Torre LA, Siegel RL, Ward EM, Jemal A. Global Cancer Incidence and Mortality Rates and Trends-An Update. Cancer Epidemiol Biomarkers Prev [Internet]. 2016 Jan [cited 2017 Feb 5];25(1):16-27. Available from: http://cebp .aacrjournals.org/cgi/pmidlookup?view=long\&pm id=26667886

6. Siegel R, Miller KD, Jemal A. Cancer statistics, 2017. CA Cancer J Clin. 2017;67(1):7-30.

7. Jemal A, Bray F, Forman D, O'Brian M, Ferlay $\mathrm{J}$, Center $\mathrm{M}$, et al. Cancer burden in Africa and opportunities for prevention. Cancer. 2012 Sep 15:118(18):4372-84.

8. Curado MP, de Souza DL. A global perspective on cancer burden in Latin America and the Caribbean. Ann Glob Health. 2014 Sep-Oct;80(5):370-7.

9. Sierra MS, Soerjomataram I, Antoni S, Laversanne $M$, Piñeros $M$, de Vries $E$, et al. Cancer patterns and trends in Central and South America. Cancer Epidemiol. 2016 Sep;44 Suppl 1:S23-S42.

10. Bray F, Piñeros M. Cancer patterns, trends and projections in Latin America and the Caribbean: a global context. Salud Pública Méx. 2016 Apr;58(2):104-17.

11. McCormack VA, Boffeta P. Today's lifestyles, tomorrow's cancers. Trends in lifestyles risk factors for cancer in low and middle-income countries. Ann Oncol. 2011 Nov;22(11):2349-57.

12. Thomas F, Fisher D, Fort P, Marie JP, Daoust S, Roche $\mathrm{B}$, et al. Applying ecological and evolutionary theory to cancer: a long and winding road. Evol Appl. 2013 Jan;6(1):1-10.

13. Higgings JPT, Altman DG, Sterne AC. Assessing risk of bias in included studies. In: Higgings JPT, Green S, editors. Cochrane Handbook for Sys- tematic Reviews of Interventions (Version 5.1.0) [Internet]. London: Cochrane.org; 2011 Mar [cited 2016 Oct 30]. Available from: http://handbook-5-1 cochrane.org/

14. Tomassetti C, Vogelstein B. Variation in cancer risk among tissues can be explained by the number of stem cell divisions. Science. 2015 Jan 2;347(6217):78-81.

15. Tomasetti C, Li L, Vogelstein B. Stem cell divisions, somatic mutations, cancer etiology, and cancer prevention. Science. 2017 Mar;355:1330-4.

16. Wu S, Powers S, Zhu W, Hannun YA. Substantial contribution of extrinsic risk factors to cancer development. Nature. 2016 Jan 7;529(7584):43-7

17. Weinberg CR, Zaykin D. Is bad luck the main cause of cancer? J Natl Cancer Inst. 2015 May 8;107(7): pii: djv125. DOI: 10.1093/jnci/djv125.

18. Potter JD, Prentice RL. Cancer risk: tumor excluded. Science. 2015 Feb 13:347(6223):727.

19. Gotay C, Dummer T, Spinelli J. Cancer risk: prevention is crucial. Science. 2015 Feb 13;347(6223):728.

20. Fox EJ, Salk JJ, Loeb LA. Exploring the implications of distinct mutational signatures and mutation rates in aging and cancer. Genome Med. 2016 Mar 17;8(1):30.

21. Sornette $D$, Favre M. Debunking mathematically the logical fallacy that cancer risk is just "bad luck". EPJ Nonlinear Biomed Physics. 2015 Dec 1;3-10.

22. Albini A, Cavuto S, Apolone G, Noonan DM. Strategies to Prevent "Bad Luck" in Cancer. JNCI J Natl Cancer Inst [Internet]. 2015 Aug 4 [cited 2016 Nov 5];107(10). Available from: https://www.ncbi.nlm .nih.gov/pmc/articles/pmid/26242894/

23. Armitage P, Doll R. The age distribution of cancer and a multi-stage theory of carcinogenesis. $\mathrm{Br} \mathrm{J}$ Cancer. 1954 Mar;8(1):1-22.

24. Hao D, Wang L, Di LJ. Distinct mutation accumulation rates among tissues determine the variation in cancer risk. Sci Rep. 2016 Jan 20;6:19458.

25. Martincorena I, Campbell PJ. Somatic mutation in cancer and normal cells. Science. 2015 Sep 25;349(6255):1483-9.

26. Petkova R, Chakarov S. The final checkpoint. Cancer as an adaptive evolutionary mechanism. J Biotech Biotechnol Equip. 2016 Feb 24;30(3):434-42.

27. DeGregori J. Challenging the axiom: Does the occurrence of oncogenic mutations truly limit cancer development with age. Oncogene. $2013 \mathrm{Apr}$ 11;32(15):1869-75

28. Rozhok Al, DeGregori J. The evolution of lifespan and age-dependent cancer risk. Trends Cancer
[Internet]. 2016 Oct [cited 2017 Apr 12];2(10):552-60. Available from: http://www.ucdenver.edu/academics/ colleges/medicalschool/departments/biochemistry/ Research/researchlabs/DeGregoriLab/Documents/ Rozhok DeGregori TrendsCancer.pdf

29. Gatenby RA, Brown J. Mutations, evolution and the central role of a self-defined fitness function in the initiation and progression of cancer. Biochim Biophys Acta. 2017 Apr;1867(2):162-6.

30. Rozhok A, DeGregori J. Toward an evolutionary model of cancer: Considering the mechanisms that govern the fate of somatic mutations. Proc Natl Acad Sci USA. 2015 Jul 21;112(29):8914-21.

31. Peto R, Roe FJ, Lee PN, Levy L, Clack J. Cancer and ageing in mice and men. Br J Cancer. 1975 Oct:32(4):411-26.

32. Kokko H, Hochberg ME. Towards cancer-aware life-history modelling. Philos Trans R Soc Lond B Biol Sci [Internet]. 2015 Jul 19 [cited 2016 Nov 23];370: pii: 20140234. Available from: http:// dx.doi.org/10.1098/rstb.2014.0234

33. Aktipis CA, Boddy AM, Jansen G, Hibner U, Hochberg ME, Maley CC, et al. Cancer across the tree of life: cooperation and cheating in multicellularity. Philos Trans R Soc Lond B Biol Sci [Internet]. 2015 Apr 30 [cited 2016 Nov 10];370(1673). pii: 20140219. Available from: http://dx.doi .org/10.1098/rstb.2014.0219

34. Boddy AM, Kokko H, Breden F, Wilkinson GS, Aktipis CA. Cancer susceptibility and reproductive trade-offs: a model of the evolution of cancer defences. Philos Trans R Soc Lond B Biol Sci [Internet]. 2015 Jun 8 [cited 2016 Nov 23];370. pii: 20140220. Available from: http://dx.doi .org/10.1098/rstb.2014.0220

35. Brown JS, Aktipis CA. Inclusive fitness effects can select for cancer suppression into old age. Phil Trans R Soc B [Internet]. 2015 [cited 2016 Nov 25];370:20150160. Available from: http://dx.doi .org/10.1098/rstb.2015.0160

36. Brown JS, Cunningham JJ, Gatenby RA. The multiple facets of Peto's paradox: a life-history model for the evolution of cancer suppression. Phil Trans R Soc B [Internet]. 2015 [cited 2016 Nov 25];370:20140221. Available from: http://dx.doi .org/10.1098/rstb.2014.0221

37. Aktipis CA, Boddy AM, Gatenby RA, Brown JS Maley CC. Life history trade-offs in cancer evolution. Nat Rev Cancer [Internet]. 2013 Dec [cited 2016 Dec 4];13(12):883-92. Available from: http:// dx.doi.org/10.1038/nrc3606

38. Hochberg ME, Noble RJ. A framework for how environment contributes to cancer risk. Ecol Lett. 2017 Feb;20(2):117-34. 
39. Greaves M. Evolutionary determinants of cancer. Cancer Discov. 2015 Aug;5(8):806-20.

40. Brinton LA, Figueroa JD, Awuah B, Yarney J, Wiafe $S$, Wood S, et al. Breast cancer in Sub-Saharan Africa: opportunities for prevention. Breast Cancer Res Treat. 2014 Apr;144(3):467-78.

41. Tammemägi MC, Katki HA, Hocking WG, Church TR, Caporaso N, Kvale PA, et al. Selection criteria for lung-cancer screening. N Engl J Med 2013; 368(8):728-36.

42. Riosmena F, Wong R, Palloni A. Migration selection, protection, and acculturation in health: a binational perspective on older adults. Demography. 2013 Jun; 50(3):1039-64.

43. Chena R, Rena S, Yiub MK, Faic NC, Cheng WS: Chinese Prostate Cancer Consortium, et al. Prostate cancer in Asia: A collaborative report. Asia J Urol. 2014 Oct; 1(1):15-29.

44. Youlden DR, Cramb SM, Yip $\mathrm{CH}$, Baade PD. Incidence and mortality of female breast cancer in Asia-Pacific region. Cancer Biol Med. 2014 Jun;11(2):101-15.

45. Jedy-Agba E, McCormack V, Adebamowo C, dos-Santos-Silva I. Stage at diagnosis of breast cancer in sub-saharian Africa: a systematic review and meta-analysis. Lancet Glob Health. 2016 Dec;4(12):e926-e35.
46. Falandry C, Bonnefoy M, Freyes G, Gilson E. Biology of cancer and aging: A complex association with cellular senescence. J Clin Oncol. 2014 Aug 20;32(24):2604-10.

47. Amadou A, Torres-Mejía G, Hainaut P, Romieu I. Breast cancer in Latin America: global burden, patterns, and risk factors. Salud Pública Méx. 2014 Sep-Oct:56(5):547-54.

48. Villarreal-Garza C, Águila C, Magallanes-Hoyos MC, Mohar A, Bargalló E, Meneses A, et al. Breast cancer in young women in Latin America: an unmet, growing burden. Oncologist. 2013;18 Suppl:26-34.

49. Ferlay J, Forman D, Mathers CD, Bray F. Breast and cervical cancer in 187 countries between 1980 and 2010. Lancet. 2012;379:1390-1.

50. Franco-Marina F, López-Carrillo L, Keating $\mathrm{NL}$, Arreola-Ornelas $\mathrm{H}$, Marie Knaul F. Breast cancer age at diagnosis patterns in four Latin American Populations: A comparison with North American countries. Cancer Epidemiol. 2015 Dec;39(6):831-7. Epub 2015 Oct

51. Rocha-Brischiliari SC, Oliveira RR, Andrade L Brischiliari A, Gravena AA, Carvalho MD, et al. The Rise in Mortality from Breast Cancer in Young Women: Trend Analysis in Brazil. PLoS One. 2017 Jan 3;12(1):e0168950.
52. Cavalli F. Cáncer. El gran desafío [Internet]. Habana: Editorial Ciencias Médicas; 2012 [cited 2016 Dec 5]. Available from: http://www.bvs.sld. cu/libros/cancer gran desafio/indice p.htm. Spanish.

\section{THE AUTHORS}

Armando E. Pérez-Cala (Corresponding author: armando.perez@infomed.sld.cu), internist with a master's degree in urgent-care medicine. Assistant professor of internal medicine and associate researcher, Joaquín Castillo Duany Military Hospital, Santiago, Cuba.

Edgar Benítez-Sánchez, physician specializing in hygiene and epidemiology, with a master's degree in infectious diseases. Instructor in hygiene and epidemiology, Joaquín Castillo Duany Military Hospital, Santiago, Cuba.

\section{Submitted: March 15, 2017}

Approved for publication: September 9, 2017 Disclosures: None 